BNL-79232-2007-CP

\title{
Heavy ion driver with non-scaling FFAG
}

\author{
A.G. Ruggiero, J. Alessi, E. Beebe, \\ A. Pikin, T. Roser, D. Trbojevic
}

Presented at the $22^{\text {nd }}$ Particle Accelerator Conference (PAC)

Albuquerque, New Mexico

June $25-29,2007$

Notice: This manuscript has been authored by employees of Brookhaven Science Associates, LLC under Contract No. DE-AC02-98CH10886 with the U.S. Department of Energy. The publisher by accepting the manuscript for publication acknowledges that the United States Government retains a non-exclusive, paid-up, irrevocable, world-wide license to publish or reproduce the published form of this manuscript, or allow others to do so, for United States Government purposes.

This preprint is intended for publication in a journal or proceedings. Since changes may be made before publication, it may not be cited or reproduced without the author's permission. 


\section{DISCLAIMER}

This report was prepared as an account of work sponsored by an agency of the United States Government. Neither the United States Government nor any agency thereof, nor any of their employees, nor any of their contractors, subcontractors, or their employees, makes any warranty, express or implied, or assumes any legal liability or responsibility for the accuracy, completeness, or any third party's use or the results of such use of any information, apparatus, product, or process disclosed, or represents that its use would not infringe privately owned rights. Reference herein to any specific commercial product, process, or service by trade name, trademark, manufacturer, or otherwise, does not necessarily constitute or imply its endorsement, recommendation, or favoring by the United States Government or any agency thereof or its contractors or subcontractors. The views and opinions of authors expressed herein do not necessarily state or reflect those of the United States Government or any agency thereof. 


\title{
HEAVY ION DRIVER WITH NON-SCALING FFAG*
}

\author{
A.G. Ruggiero, J. Alessi, E. Beebe, A. Pikin, T. Roser, and D. Trbojevic \\ Brookhaven National Laboratory, Upton, NY 11973, U.S.A.
}

\section{Abstract}

We explore the possibility of using two non-scaling FFAG accelerators for a high power heavy-ion driver as an alternative to a superconducting Linac [1]. Ions of Uranium 238 are accelerated to a kinetic energy of 400 $\mathrm{MeV} / \mathrm{u}$ and a total power of $400 \mathrm{kWatt}$. Different modes of acceleration have been studied: at 1 and $10 \mathrm{kHz}$ repetition rate, and for Continuous Wave production. The following is a summary of the study. More details of the study can be found in [2].

\section{INTRODUCTION}

As an alternative to the Super-Conducting Linac (SCL) approach [1] we studied acceleration of ions of Uranium in a pair of Fixed-Field Alternating-Gradient (FFAG) accelerators for the production of Rare Isotopes. We have adopted the Non-Scaling Lattice with a Linear Field Profile. This lattice does not compensate for the chromaticity change but makes the magnet lattice design more compact [3]. An important feature of FFAG accelerators is that the magnets are kept at constant fields; thus the acceleration rate is limited by the RF system itself. In the case of acceleration of low-energy heavy particles the beam velocity varies considerably during the acceleration cycle. For fast acceleration, frequencymodulated RF cavity systems will not do the job. An alternative is broadband, constant frequency RF cavities [4]. Another approach is the Harmonic Number Jump (HNJ) [5]. In this case the cavities have also constant frequency but in the range of hundreds $\mathrm{MHz}$. Ultimately the HNJ method could be used for a continuous beam mode of operation.

\section{POSSIBLE FFAG SCENARIOS}

Possible scenarios make use of either one or two FFAG rings as shown in Figure 1. The Scenario with a single ring (not shown) makes use of the first half of the SCL design up to the energy of $80 \mathrm{MeV} / \mathrm{u}$. The High- $\beta$ Section is entirely replaced by one FFAG that accelerates the beam from 80 to $400 \mathrm{MeV} / \mathrm{u}$. We shall not report here further on the single FFAG scenario [2]. In the two FFAG ring scenario an extra ring is added for acceleration between 15 and $80 \mathrm{MeV} / \mathrm{u}$. The two rings have the same circumference and they can be located in the same enclosure either on top of each other or concentric. The injection and extraction energies of each ring have been determined by setting a momentum range for acceleration around $\pm 40 \%$. The Front-End and the Low- $\beta$ Section of

*Work performed under Contract No. DE-AC02$98 \mathrm{CH} 10886$ with the U.S. Department of Energy the SCL design are retained, but an extra section is added for acceleration from 9.4 to $15 \mathrm{MeV} / \mathrm{u}$. To get the required average beam intensity the accelerator complex. is to be capable to accelerate multiple charge states, around 70 in FFAG-1 and 90 in FFAG-2.

\section{DESIGN OF FFAG RINGS}

The two FFAG rings have the same circumference and the same identical lattice structure summarized in Table 1. Each of them is made of an unbroken sequence of FDF triplets as shown in Figure 2. The lattice functions on the injection orbit are shown in Figure 3. There are two major drifts: a long one, $s$, and a minor one, $g$ that separate the magnets. These are sector magnets with parallel entrance and exit faces. The field profile is linear, namely a superposition of a dipole and a quadrupole field. We have considered [2] several periodicities but report here only the case of 80 periods. A lower periodicity makes the lattice unstable at the high-energy end, and a higher periodicity is unpractical. Two main parameters are the

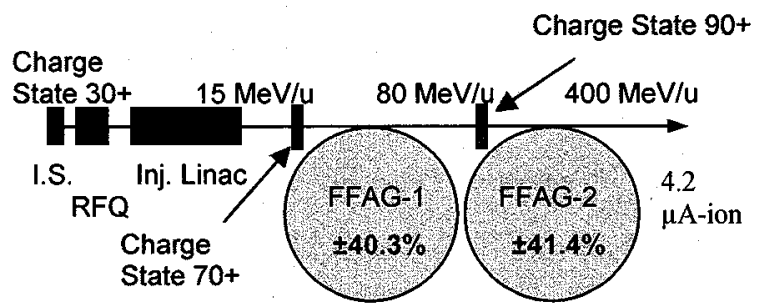

length $s$ of the long drift that one desires long enough to accommodate RF cavities, and the radial width $w$ required for the momentum excursion.

Figure 1: FFAG-based accelerator for RI production

Table 1. Structure of the FFAG Rings

$\begin{array}{ll}\text { Circumference } & 204 \mathrm{~m} \\ \text { Number of Periods } & 80 \\ \text { Period Length } & 2.55 \mathrm{~m} \\ \text { Long Drift } s & 1.089 \mathrm{~m} \\ \text { Short Drift } g & 0.129 \mathrm{~m} \\ \text { Radial Width } w & 11.2 \mathrm{~cm} \\ \text { F-Sector Arc Length, } \mathrm{m} & 0.301 \\ \text { D-Sector Arc Length, m } & 0.602\end{array}$

\section{BROADBAND CAVITIES AT $1 \mathrm{KHZ}$}

Table 2 summarizes the main parameters for a repetition rate of $1 \mathrm{kHz}$. Broadband, fixed-frequency $\mathrm{RF}$ cavities (Finemet) have been developed at KEK in Japan. They are typically $60 \mathrm{~cm}$ long, with a peak voltage of 20 $k$ Volt in the middle of the frequency range. One long straight section $s$ can accommodate a multi-gap cavity for a total of $20 \mathrm{kVolt}$ peak. Thus one needs 40 broadband 
cavities for a total of $0.8 \mathrm{MVolt}$ in the FFAG-1 ring, and 80 broadband cavities for a total of 1.6 MVolt in the FFAG-2 ring. Moreover the cavities are demanding in power as they dissipate more than $100 \mathrm{kWatt}$. The total dissipated power is thus several MWatt, considerably higher than the actual beam RF power of only a fraction of one MWatt.

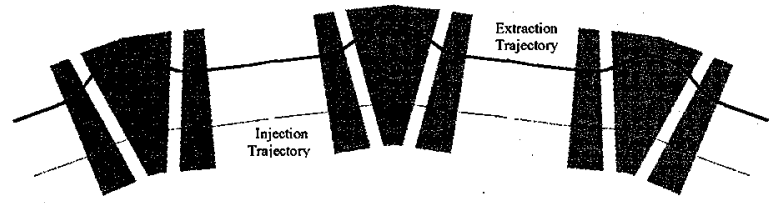

Figure 2: The FDF triplet period of the FFAG rings

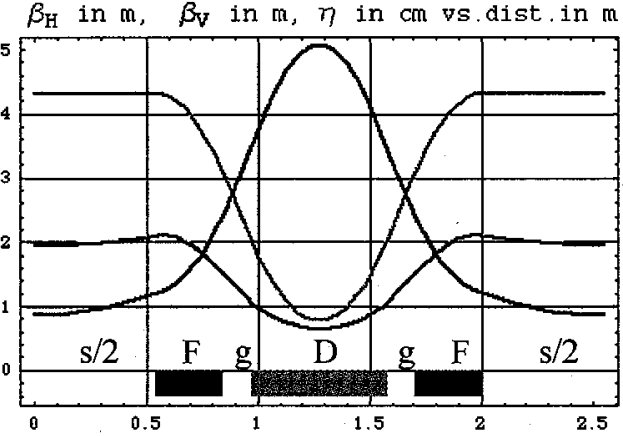

Figure 3: Lattice Functions along the length of a Period

Table 2. Main Parameters at $1 \mathrm{kHz}$

\begin{tabular}{|l|l|c|c|}
\hline & & FFAG-1 & FFAG-2 \\
\hline Kin. Energy & $\mathrm{MeV} / \mathrm{u}$ & $15-80$ & $80-400$ \\
\hline Revol. Freq. & $\mathrm{MHz}$ & $0.26-0.57$ & $0.57-1.05$ \\
\hline Emitt. full nor. & $\pi \mathrm{mm}-\mathrm{mrad}$ & 100 & 100 \\
\hline Bunch Area & $\mathrm{eV} / \mathrm{u}-\mathrm{s}$ & 0.02 & 0.02 \\
\hline Spc-Chg $\Delta v$ & & $0.02-0.01$ & $0.02-0.01$ \\
\hline Harmon. No. & & 6 & 6 \\
\hline RF Frequency & $\mathrm{MHz}$ & $1.59-3.42$ & $3.43-6.27$ \\
\hline pk RF Voltage & $\mathrm{MVolt}$ & 0.8 & 1.6 \\
\hline RF Phase & & $60^{\circ}$ & $60^{\circ}$ \\
\hline Accel. Period & $\mathrm{ms}$ & 0.758 & 0.726 \\
\hline No. of Revol. & & 319 & 611 \\
\hline Ave. Currunt & $\mathrm{mA-ion}$ & $1.09-2.40$ & $2.40-4.40$ \\
\hline
\end{tabular}

\section{INJECTION ISSUES AT $1 \mathrm{KHZ}$}

The beam circulating current at injection into FFAG-1 is $1.1 \mathrm{~mA}$-ion. Charge exchange method is not possible with heavy ion beams. The old fashioned betatron stacking injection is also not easily possible with beam from a high intensity ECR source that has a quite large emittance. The addition of an Accumulator Ring sitting in front of the two FFAG rings does not ameliorate the situation. An alternative is to transfer the beam from the ECR in a following EBIS structure where it can be stored and space-charge neutralized by the electron beam, as shown in Figure 4. Once enough ions have been accumulated the beam is extracted from the EBIS in a single pulse $3.5 \mu$ s long and transported through the RFQ and Linac prior to injection into the FFAG ring. Thus over a period of one millisecond the beam is continuously injected from the ECR and stored into EBIS. At the end of that period of time $2.63 \times 10^{10}$ ions have been accumulated preserving their charge states.

The full beam normalized emittance should not exceed

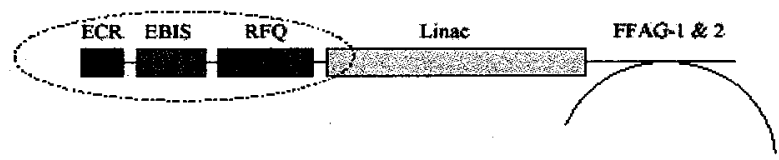

Figure 4. ECR-EBIS-RFQ Front-End

$100 \pi \mathrm{mm}$-mrad to limit the height of the magnet gap, and not be less than $10 \pi \mathrm{mm}$-mrad to avoid a space-charge tune depression exceeding 0.2 at injection.

\section{ACCELERATION BY HNJ}

A higher repetition rate can be achieved with the HNJ method that allows the use of superconducting RF cavities at very high constant frequency. Acceleration requires a programmed energy gain that varies between cavity crossings to allow the change of the transit time between cavities that corresponds to the jump of one or more RF harmonics. It is to point out that, since the harmonic number $h$ reduces during acceleration, the number of beam bunches at injection into the first ring cannot be larger than the harmonic number at extraction from the second ring. The FFAG ring has $M$ equally spaced localized groups of cavities each with $\mathrm{N}_{C}$ cavities. Each group of cavities applies an energy gain that is a function of the beam energy at the n-th crossing

$$
\begin{aligned}
\Delta \mathrm{E}_{\mathrm{n}+1} & =\mathrm{E}_{0} \beta_{\mathrm{n}}{ }^{2} \gamma_{\mathrm{n}}^{3} \Delta \mathrm{h} /\left(1-\alpha_{\mathrm{p}} \gamma_{\mathrm{n}}^{2}\right) \mathrm{h}_{\mathrm{n}} \\
& =(\mathrm{Q} / \mathrm{A}) \mathrm{e} \mathrm{V}_{\mathrm{n}} \sin \phi_{\mathrm{RF}}
\end{aligned}
$$

where $E_{0}$ is the ion rest energy, $\beta_{n}$ and $\gamma_{n}$ the velocity and energy relativistic factors at the $n$-th crossing, $\alpha_{p}$ the momentum compaction, $h_{n}$ the harmonic number between the (n-1)-th and the $n$-th crossing, and $\phi_{\mathrm{RF}}$ the constant RF phase. Finally $\Delta h=h_{n+1}-h_{n}<0$ is the harmonic number jump. Table 3 gives the main parameters for $\Delta h=-1$.

Table 3. Main Parameters at $10 \mathrm{kHz}$ with $\mathrm{HNJ}$

\begin{tabular}{|l|c|c|}
\hline & FFAG-1 & FFAG-2 \\
\hline Bunch Area & \multicolumn{2}{|c|}{$10 \mu \mathrm{eV} / \mathrm{u}-\mathrm{s}$ rms } \\
\hline Emittance & $\begin{array}{c}25 \pi \mathrm{mm}-\mathrm{mrad} \text { full normalized } \\
(\Delta \nu=0.2 \text { sp.ch. })\end{array}$ \\
\hline $\mathrm{f}_{\mathrm{RF}}$ & $806.03 \mathrm{MHz}$ & $803.93 \mathrm{MHz}$ \\
\hline h (total) & $\mathbf{8 \times ( 3 8 8 - 1 7 6 )}$ & $4 \times(352-192)$ \\
\hline No. Cavities & $\begin{array}{c}\mathbf{8} \text { groups } \\
2 \text { cavities each }\end{array}$ & $\begin{array}{c}4 \text { groups } \\
4 \text { cavities each }\end{array}$ \\
\hline RF Phase & $30^{\circ}$ & $60^{\circ}$ \\
\hline pk RF Voltage & $2 \mathrm{MV} /$ Cavity & $8 \mathrm{MV} /$ Cavity \\
\hline Acc. Period & $74.0 \mu \mathrm{s}$ & $54.0 \mu \mathrm{s}$ \\
\hline no. Revol. & $26+4 / 8$ & 40 \\
\hline
\end{tabular}




\section{SUPERCONDUCTING RF CAVITIES}

The voltage profile is about linear with the radial displacement of the beam during acceleration. Cavities have a single cell and are all tuned independently. The gap is related to the RF wavelength $\lambda_{R F}$ by the relation $g=$ $\lambda_{R F} \beta_{0} / 2$ where $\beta_{0}$ is a nominal value the same for all the cavities in the same ring. During the $\mathrm{n}$-th cavity crossing the peak total voltage $V_{n}$ is related to the surface axial field $\xi_{\mathrm{n}}$ through the relation $V_{\mathrm{n}}=\mathrm{g} \xi_{\mathrm{n}} \operatorname{TTF}\left(\beta_{0} / \beta_{\mathrm{n}}\right)$ where TTF is the Transit Time Factor. The surface axial field $\xi_{\mathrm{n}}$ is plotted in Figure 5, and is about the same for both rings. It can be obtained with three cavities located next to each other, one operating in a $\mathrm{TM}_{01}$ mode at the constant field $\xi=16 \mathrm{MVolt} / \mathrm{m}$ corresponding to the central value, and the other two in $\mathrm{TM}_{11}$ mode with a linear field $\xi= \pm 6$ $\mathrm{MVolt} / \mathrm{m}$ corresponding to the slope of the plot.

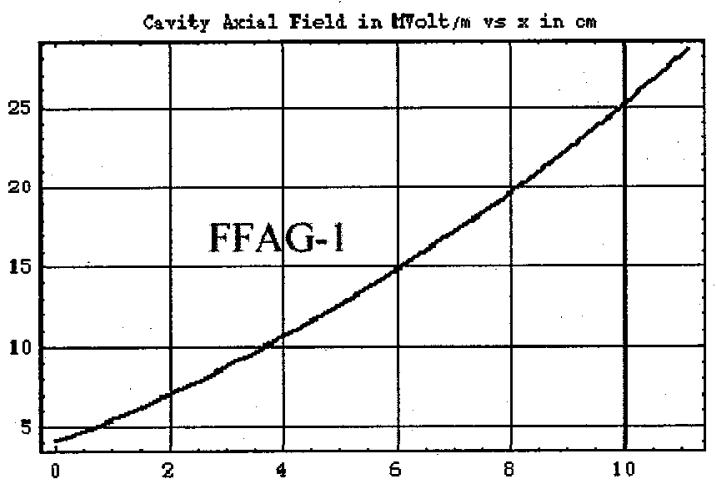

Figure 5. Total Axial Field for each RF Cavity

\section{INJECTION ISSUES AT $10 \mathrm{KHZ}$}

The circulating current at injection is now $440 \mu \mathrm{A}$-ion, taking into account the fact that each injected turn has a duration shorter than the revolution period. It may now be possible also to perform betatron stacking in a separate Accumulator Ring placed in front of the two FFAG rings. The requirements are shown in Table 4 that assumes $n=$ 20 turns to be injected, with each turn lasting $0.96 \mu \mathrm{s}$ against the revolution period of $3.8 \mu \mathrm{s}$. We have assumed a normalized full beam emittance at the end of stacking $\varepsilon_{\mathrm{n}}$ $=100 \pi \mathrm{mm}$-mrad. This corresponds to a required acceptance $A=560 \pi \mathrm{mm}$-mrad with a stacking efficiency $\eta=40 \%$, based on experience with multi-turn injection with ions of gold in the AGS Booster, and to a full magnet gap $3 \mathrm{~b}$ given in Table 4 . The single turn intensity $I_{s}$ is somewhat large and still maybe over what it can reasonably be delivered from the ECR ion source. Thus of course stacking the beam from the ECR in a subsequent EBIS is still possible as described earlier, and would actually perform even better. Over a period of $100 \mu$ s the beam is continuously injected and stored. At the end of that period of time $2.63 \times 10^{9}$ ions have been accumulated. The pulse is then extracted with duration of $0.96 \mu \mathrm{s}$. The full beam normalized emittance should not exceed $100 \pi \mathrm{mm}$-mrad to limit the height of the magnet gap, and not be less than $25 \pi \mathrm{mm}$-mrad to avoid a space charge-tune depression exceeding 0.2 .
Table 4. Betatron Stacking in separated Accumulator Ring at $\mathrm{f}_{\text {rep }}=10 \mathrm{kHz}$ into FFAG-1

$\begin{array}{ll}A & 560 \pi \mathrm{mm}-\mathrm{mrad} \\ \varepsilon_{\mathrm{sn}} / \beta \gamma & 11.2 \pi \mathrm{mm}-\mathrm{mrad} \\ \text { Pulse Frequency } & 0.2597 \mathrm{MHz} \\ \eta & 40 \% \\ \mathrm{I}_{\mathrm{s}} & 22 \mu \mathrm{A}-\text { ion } \\ 3 \mathrm{~b}=3\left(A \beta_{\mathrm{V}}\right)^{1 / 2} & 165 \mathrm{~mm} \\ \mathrm{~T}_{\mathrm{s}} & 77 \mu \mathrm{s}\end{array}$

\section{CW MODE OF OPERATION}

A more convenient mode of operation is the Continuous Wave (CW) where the beam is continuously injected, accelerated and transferred to the Target. The continuous injection will require that ions occupy simultaneously all orbits. The same RF system with the HNJ method still applies. The required average current on the target is $4.2 \mu \mathrm{A}$-ions. This equals the circulating current at the moment of extraction from the last orbit of the second FFAG ring. This suggests the following mode of operation. The ECR generates an open sequence of ion pulses at the repetition rate of the injection frequency in FFAG-1 ring, that is with a periodicity $3.851 \mu \mathrm{s}$, but each with a duration $0.957 \mu$ s corresponding to the revolution period at the last orbit of the last ring. The average current within a pulse is $4.2 \mu \mathrm{A}$-ion. There are 55 bunches in each pulse and the bunching frequency is $57.5 \mathrm{MHz}$, that is there is one bunch every $14 \mathrm{RF}$ buckets at $805 \mathrm{MHz}$. This time structure is preserved throughout the acceleration cycle, except that the beam pulses get closer. to each other and eventually collapse side by side as a real continuous beam on the main Target. The number of ions per turn is $2.51 \times 10^{7}$ and the full beam normalized emittance $2 \pi \mathrm{mm}$-mrad. The main $\mathrm{RF}$ and beam parameters for the continuous mode of operation are listed in Table 5.

Table 5. RF Requirements and Beam Parameters for CW mode of Operation

$\begin{array}{lll} & \text { FFAG-1 } & \text { FFAG-2 } \\ \text { Cavity Groups } & 8 & 4 \\ \text { Cavities per Group } & 2 & 4 \\ \beta_{0} & 0.22 & 0.50 \\ \text { Cavity Gap, cm } & 4.1 & 9.3 \\ \text { RF Phase } & 30^{\circ} & 60^{\circ} \\ \text { RF Voltage / Cavity } & 2 \text { MVolt } & 1 \text { MVolt } \\ \text { Orbit Separation, mm } & 0.23-3.4 & 0.30-2.8\end{array}$

\section{REFERENCES}

[1] P. Ostroumov, Phys. Rev. STA\&B 5, 030101 (2002)

[2] A.G. Ruggiero, BNL Report, C-A/AD/279, June 2007

[3] A.G. Ruggiero, The Int. Workshop on FFAG Accel., page 31, Dec. 5-9, 2005, KURRI, Osaka, Japan

[4] Y. Yamazaky, HB2006 Proceedings, Tsukuba, Japan, May 29-June 4, 2006

[5] A.G. Ruggiero, Phys. Rev. STA\&B 9, 100101 (2006) 